RUNNING HEAD: Interventions for communicating consent

\title{
A test of three interventions to promote people's communication of their consent for organ donation
}

\author{
Melissa K. Hyde ${ }^{1,2,3}$ and Katherine M. White . $^{2,3}$
}

${ }^{1}$ Griffith Health Institute, Griffith University, Brisbane, Australia.

${ }^{2}$ School of Psychology and Counselling, Queensland University of Technology, Brisbane, Australia.

${ }^{3}$ Institute of Health and Biomedical Innovation, Queensland University of Technology, Brisbane, Australia

Abstract word count: 200; Text word count: 5995; Tables: 3, Figures: 2

Correspondence concerning this article should be addressed to: Dr Melissa K. Hyde, Griffith Health Institute and School of Applied Psychology, Griffith University, 176 Messines Ridge Road, Mt Gravatt, Queensland, 4122, Australia. *Email: melissa.hyde@ griffith.edu.au * Please note that this research was conducted while the corresponding author was employed at QUT.

\section{Acknowledgements}

This study was supported by a Queensland University of Technology, Vice Chancellor's Postdoctoral Research Fellowship Support Grant. The authors have no conflicts of interest to declare. 


\begin{abstract}
People's decision to join an organ donor registry and have a discussion with family about their organ donation preference increases the likelihood that their family will consent to donation of their organs. This study explores the effectiveness of three interventions compared to a control condition to increase individual consent (registering and discussing donation wishes) for organ donation. Australian residents who had not previously communicated their consent $(\mathrm{N}=177)$ were randomly allocated to complete an online survey representing either an extended theory of planned behaviour motivational intervention (strengthening intention via attitudes, subjective norms, control, moral norms, and identity), a volitional intervention using constructs from the health action process approach (strengthening the translation of intentions into action using action plans and coping plans), a combined motivational and volitional intervention, or a control condition. Registering, but not discussing, intentions increased in the motivational compared to non-motivational conditions. For joining the organ donor registry, the combination of strengthening intentions (motivational) as well as forming specific action (when, where, how, and with whom for discussing) and coping (listing potential obstacles and how these may be overcome) plans (volitional) resulted in significantly higher rates of self-reported behaviour. There was no evidence for this effect on discussion.
\end{abstract}

Keywords: organ donation, consent, theory of planned behaviour, health action process approach, action plans, coping plans, intervention 
Bridging the gap between human organ supply and demand for transplantation is critical in countries with opt-in systems, particularly Australia which has one of the lowest donation rates in the world (14.9 donors per million population; DonateLife 2012a). Although Australians aged 18 years and over can join the Australian Organ Donor Registry to record their consent for or objection to organ donation, in practice, donation will not proceed without the consent of family members for donation of their loved one's organs (DonateLife, 2012b). Strategies to counteract family non-consent for organ donation, a factor widely acknowledged as preventing organ recovery from medically suitable donors in Australia and in other countries with opt-in systems (National Clinical Taskforce on Organ Donation [NCTOTD], 2008; Rosenblum, Horvat, Siminoff, Prakash, Beitel, \& Garg, 2011), are, therefore, integral to increasing human organ supply. Attitudes toward organ donation are highly positive (e.g., Morgan \& Miller, 2002; Nijkamp, Hollestelle, Zeegers, van den Borne, \& Reubsaet, 2008), yet when Australian family members are approached for authority to donate their loved one's organs (regardless of their loved one's legally recorded consent), approximately $50 \%$ of families refuse consent (DonateLife, 2012a).

Among the factors proposed to increase family members' consent to a request for donation of their loved one's organs, family members' prior knowledge of their loved one's documented decision on a donor register/card or prior conversation about donation wishes is paramount (Siminoff, Gordon, Hewlett, \& Arnold, 2001). Despite the importance of communicating organ donation wishes, $40 \%$ of Australians do not know the donation wishes of their loved ones and fewer than $20 \%$ have had a memorable conversation about donation with family (DonateLife, 2012a). Strategies to increase communication of donation wishes and subsequent family consent for organ donation are, therefore, vital to increase donation rates (NCTOTD, 2008). This study tests three theoretically informed interventions to increase people's communication of their organ donation wishes to their family. 


\section{Predicting organ donation communication intentions}

Most research to date has identified the psychosocial predictors of people's intentions to communicate consent for organ donation, and less so behaviour, via joining a registry/ signing a donor card or talking with family (Nijkamp et al., 2008). This focus has included the development of decision-making models which use elements from the theory of planned behaviour (TPB; Ajzen, 1991) such as attitude and subjective norm (Morgan \& Miller, 2002).

Theory of planned behaviour. Briefly, the TPB proposes intention (readiness to act), along with perceived behavioural control (PBC) in situations where behaviour is volitional, as the central and most proximal determinants of behaviour. Intention is determined by an individual's attitude (positive or negative evaluation), subjective norm (perceived normative pressure/support from important others), and PBC (perceived ease or difficulty) for the behaviour of interest (Ajzen, 1991). Stronger attitudes, norms, and PBC, are expected to result in greater behavioural intentions and ultimately behaviour. Research generally supports the use of the TPB to understand people's decisions to join a donor registry/sign a donor card (e.g., Godin, Bélanger-Gravel, Gagné, \& Blondeau, 2008; Hyde \& White, 2009; Park \& Smith, 2007) and talk with family (e.g., Hyde \& White, 2009; Park \& Smith, 2007), and explains up to $60 \%$ of the variance in people's communication intentions. Organ donation decisions may also be informed by an individual's moral responsibility or conviction to donate organs/communicate consent (i.e. moral norm; Godin et al., 2008) and evaluations of self as the kind of person who would donate/communicate consent (i.e. self-identity; Hyde \& White, 2009). Although there are a range of additional factors such as demographic factors, knowledge, altruism (Morgan \& Miller, 2002), anticipated regret (O'Carroll, Foster, McGeechan, Sandford, \& Ferguson, 2011), and non-cognitive factors such as disgust (e.g., ick factor; Morgan et al., 2008; O'Carroll et al., 2011), bodily integrity, and medical mistrust (Morgan et al., 2008) that may inform people's organ donation decisions, moral norm and 
self-identity are the most consistent (Godin et al., 2008; Hyde \& White, 2009). Identifying the key predictors of people's intentions to communicate organ donation wishes is important; however, intentions do not always translate into behaviour (Schwarzer, 2008) and few studies examine the intention-behaviour relationship in this context (Nijkamp et al., 2008).

\section{Strengthening the intention-behaviour relationship for organ donation communication}

Intentions alone may not be sufficient to ensure behaviour occurs, particularly in situations where the individual anticipates difficulty performing behaviour. For instance, during a conversation with family about organ donation, an individual may encounter a difference in opinion, a challenge to justify his or her decision, or a question he or she cannot answer (e.g., Thompson, Robinson, \& Kenny, 2004). Furthermore, forgetfulness, laziness, or lack of motivation are reasons cited by individuals who have not communicated their donation wishes (e.g., Hyde \& White, 2007).These experiences serve as barriers to continuing a productive discussion or to joining the organ donation registry which may prevent an individual from expressing his or her consent fully.

Action and coping plans. To facilitate the translation of intentions into behaviour and to overcome barriers to behavioural performance, the Health Action Process Approach (HAPA) includes both action planning (akin to implementation intentions) and coping planning (Schwarzer, 2008; Sniehotta, Scholz, \& Schwarzer, 2006; Sniehotta, Schwarzer, Scholz, \& Schüz, 2005). Action planning involves detailing a specific plan about when, where, and how the individual will perform behaviour which serves as a cue in memory to ensure the individual recognises an opportunity to act when it arises (Schwarzer, 2008). Coping planning involves considering potential barriers that may be encountered as well as the generation of specific strategies to overcome these barriers. These two post-intentional variables operate in conjunction to improve the likelihood that behaviour will occur. For example, Sniehotta et al. (2006) compared the effectiveness of two planning interventions and 
a control group (no plans formed) in increasing physical activity in a sample of patients with coronary heart disease undergoing residential cardiac rehabilitation treatment. In the action planning intervention, participants used a planning sheet to form up to three plans detailing when, where, and how their physical activity would occur. For the combined action and coping planning intervention, in addition to forming action plans, participants formed up to three coping plans detailing potential strategies they could use to overcome any barriers that may prevent them from undertaking physical activity. Results of the brief-interventions showed that participants allocated to the combined action and coping planning intervention reported the most exercise at follow up compared to other participants (Sniehotta et al., 2006).

\section{The present study}

With some notable exceptions (e.g., Siegel, Alvaro, Crano, Lac, Ting, \& Jones, 2008), very little research presents theoretically-based interventions to increase organ donation communication. Where these interventions do exist, they are mostly educational in nature and focused on joining a donor registry/signing a donor card rather communicating wishes to family. To date, no studies have used the TPB, action plans or coping plans to inform a motivational and/or volitional organ donation communication intervention. This study tests three interventions: an extended TPB-based motivational intervention to strengthen people's communication intentions (Sheeran \& Silverman, 2003), a volitional intervention to increase communication behaviour using action (plans about when, where, how, and with whom for discussing, the behaviour will occur) and coping (plans detailing how obstacles to communicating can be overcome) planning constructs from the HAPA (Schwarzer, 2008; Sniehotta et al., 2006), and a combined intervention.

Hypotheses. In formulating our hypotheses we draw upon the specifications of the theoretical models used (Ajzen, 1991; Schwarzer, 2008) and previous findings (e.g., Sneihotta et al., 2006). Consistent with the TPB (Ajzen, 1991), it is hypothesized that participants 
exposed to the extended TPB motivational intervention will have greater intentions to register and discuss than participants not exposed to a motivational intervention (H1). ${ }^{1}$ Consistent with evidence that formulating plans strengthens the likelihood that people will act on their intentions (e.g., Schwarzer, 2008), it is expected also that a greater proportion of participants exposed to an intervention with a volitional component (action and coping plans) will selfreport having registered and discussed their donation wishes compared to participants not exposed to a volitional intervention (H2). Finally, in accordance with Sniehotta et al.'s.(2006) finding that a combined action and coping planning intervention was most effective to increase behaviour, it is expected that participants in the combined motivational/volitional intervention will self-report the most registering and discussing behaviour compared to all other conditions (H3).

\section{Method}

\section{Design}

This study comprised a prospective between groups design to compare intentions and behaviour across the intervention (and control) conditions. Using the design of Sheeran and Silverman's (2003) study where three interventions (a motivational extended-TPB intervention, a volitional implementation intention intervention, and a combined intervention) were compared to increase attendance at a workplace fire safety training course, each intervention was embedded within an online survey. Upon accessing the survey link, participants were allocated randomly, based on a computer generated sequence, to complete an online survey (Time 1) representing one of four conditions: a motivational intervention (C1), a volitional intervention (C2), a combined motivational/volitional intervention (C3), and a control condition (C4). Participants completed questions related to registering only if they had not previously registered their consent on the Australian Organ Donor Register (AODR). Similarly, participants completed the questions about discussing donation wishes only if they 
had not previously had a conversation with their family member/s about organ donation in which they specifically expressed their donation preference. Participants consenting to follow-up (Time 2) self-reported their communication behaviour 1 month later. Responses were matched using a participant generated code. In this study, we focus only on those participants who responded to both the Time 1 and the Time 2 follow-up online surveys.

\section{Intervention conditions.}

Motivational intervention. The motivational intervention was derived from Sheeran and Silverman (2003) and adapted for use in the current study. The motivational intervention was designed to strengthen people's intentions to communicate by encouraging supportive attitudes and norms, and heightened perceptions of control toward communication, moral obligation to communicate and perceptions of communication as consistent with the selfconcept. The motivational intervention was included at the beginning of the survey prior to survey questions ( $\mathrm{C} 1$ and $\mathrm{C} 3)$. Participants read the following paragraph:

"Please try to register your organ donation preference and tell your family about your decision in the next month. Letting people know about your organ donation preference to donate or not donate is important - it is vital to ensure that your wishes are respected. By letting others know your preference for organ donation you will improve the efficiency of the donation process and save your family from having to make the decision for you in a time of great stress and sadness. Your family will value the fact that you have told them about your donation preference and will likely share their own organ donation decision with you. Every Australian should register their consent/non-consent for donation on the AODR and tell their family about their decision because it is the right thing to do. If you know your facts about organ donation and use everyday situations to start the conversation (e.g., a TV show about organ donation), you will find that you will feel confident and comfortable telling your family your organ donation preference. If you have all the details you need to register (e.g., Medicare 
card) prepared in advance, you will find it extremely easy to register your consent/nonconsent on the AODR. Recording your organ donation decision on the donor register and sharing your donation decision with family shows others that organ donation is important to you and that you care about your family".

Volitional intervention. The volitional intervention was also derived from Sheeran and Silverman (2003) who used implementation intentions to increase behaviour; however, we adapted this condition to suit the context of our study and to include an exercise where participants created both action and coping plans to strengthen behaviour (Schwarzer, 2008; Sniehotta et al., 2006). The volitional interventions for registering and for discussing were embedded after the questions relating to each of the respective behaviours (C2 and C3). For action planning, participants filled in the blanks in a statement for registering and/or discussing which specified when, where, and how (and with whom in the case of discussing) communication of their donation wishes would occur. For coping planning, participants listed three obstacles that may interfere with their plans and suggested three solutions they could use to successfully overcome the identified barriers. Participants received an example to assist them in forming their action and coping plans and were encouraged to memorise their plans, to imagine the situation and actions they planned to take, and commit to action.

\section{Participants}

In total, 177 Australian residents (104 females, 73 males) who were mostly Caucasian $(n=170)$ and ranged in age from 18 to 80 years $(M=47.36$ years; $S D=14.91)$ provided responses at both time points. ${ }^{2}$ These participants had either not registered their consent on the AODR but had discussed their decision $(n=103)$, had not previously discussed their decision but had registered $(n=54)$, or had not previously registered or discussed their donation preference $(n=40)$ (Figure 1). Table 1 presents the demographic characteristics for the sample based on the condition participants were allocated to. 


\section{Procedure}

For inclusion in the study, participants were required to be an Australian resident aged 18 years and older and have not previously joined the AODR or discussed with family their organ donation wishes. Following university ethics approval, we used a range of recruitment methods in an attempt to obtain a representative sample of participants across Australia. Initially, survey invitations were delivered via the postal service's unaddressed mail service (delivery of flyers to community residences in targeted areas without requiring an address); resulting in a poor response rate of 2.2\% (4000 flyers were mailed resulting in 88 responses; however, there is no way to verify all 4000 flyers were received). Additional recruitment methods included delivering survey invitations via online mailing lists (university alumni and workplace mailing lists), posting on community websites, and snowballing to distribute the survey link. The methods used precluded calculation of an accurate response rate. The surveys were hosted via the university's KeySurvey secure site, took approximately 20-30 minutes to complete, were anonymous and confidential, and participants received entry into a prize draw to win one of five AUD\$100 department store gift cards as compensation for their time.

\section{Measures}

\section{Time 1 Measures.}

Prior to presentation of Time 1 measures, participants read a definition of registering and discussing (Figure 2). Participants were then presented with identical corresponding extended TPB measures regardless of the condition they were allocated to, and were directed to answer only those questions related to the behaviour/s they had not previously performed (participants who had registered prior to the study did not answer questions about registering).

Extended TPB measures. The extended TPB measures used in the Time 1 survey (Ajzen, 1991; Hyde \& White, 2009) were measured on 7-point response scales (scored 1 strongly disagree to 7 strongly agree) unless specified otherwise. Some negatively-worded 
items (reverse scored) were included to reduce response bias. Five semantic differential items for each behaviour assessed Attitude (e.g. "For me to discuss my organ donation decision with my partner/family members in the next month would be": worthless-valuable, good-bad). For each respective behaviour, scores for the attitude questions were summed and then averaged to create an attitude scale that was reliable $\left(\alpha_{\text {reg }}=.92 ; \alpha_{\text {disc }}=.95\right)$. Three items comprised the Subjective Norm scale for each behaviour (e.g. "Most people who are important to me would approve of me registering my decision in the next month") $\left(\alpha_{\text {reg }}=.82 ; \alpha_{\text {disc }}=.82\right)$. Four items comprised the $P B C$ scale for each behaviour (e.g. "It would be easy for me to register my decision in the next month") $\left(\alpha_{\text {reg }}=.74 ; \alpha_{d i s c}=.84\right)$. Four items measured Moral Norm for each behaviour (e.g., "It is in accordance with my principles to discuss my decision in the next month") $\left(\alpha_{\text {reg }}=.90 ; \alpha_{\text {disc }}=.93\right)$. Two items (e.g., "I am the type of person who would communicate my organ donation decision", scored completely false/completely true) measured Self-Identity (i.e. a communicator identity), $r=.68, p<.001$. Intention comprised three items for each behaviour ("I intend to ...", "I will try to ...", and "It is likely that I will..." discuss my decision in the next month) $\left(\alpha_{\text {reg }}=.97 ; \alpha_{\text {disc }}=.94\right)$.

\section{Time 2 Measures.}

Participants providing contact details and consent for follow-up were invited to complete the Time 2 survey. Based on Time 1 responses, those participants who indicated they had not registered previously received a survey containing questions related to registering. Similarly, participants indicating they had not discussed their donation wishes prior to the study received a survey with questions about discussing. Participants who had not previously registered or discussed received a survey with questions for both behaviours.

Registering behaviour. One item assessed participants' self-reported registering behaviour in the 1-month follow-up period: "In the past month did you register your consent/ refusal to be an organ donor on the Australian Organ Donor Register?", scored 0 no and 1 yes. 
If participants reported they had registered their consent/non-consent in the previous month, they were asked to indicate when (day/time), where (place/situation), and how they registered.

Discussing behaviour. One item assessed participants’ self-reported discussing behaviour in the previous month: "In the past month did you discuss your specific organ donation preference with a partner, family member, or significant other?", scored 0 no, 1 yes. If participants responded yes, they were asked to list who they told, when (day/time) and where (place/situation) they talked about it and how the conversation started. An additional question was included for discussing to serve as a memory prompt and to account for people who may have more than one discussion about donation. Participants chose from a list those people with whom they had communicated their organ donation preference (partner/spouse, Mother, Father, close friend/s, brother/sister, another relative/guardian, child/ren, other).

\section{Data analyses}

Participants who had not previously registered their donation preference on the AODR were included for analyses related to registering $(n=143)$ and participants who had not previously discussed their specific donation preference with family were included for analyses related to discussing ( $n=94$ ) (Figure 1). Initially, we conducted descriptive and frequency analyses to describe the characteristics of the sample (Table 1) as well as the identified barriers and solutions for registering and discussing. We conducted independent groups t-tests or Pearson's chi-square tests (via Crosstabs) to ensure the key demographic characteristics (age, gender, ethnicity) across conditions did not differ significantly. Prior to testing H1, we checked for differences between scores on the extended TPB constructs in the motivational compared to non-motivational intervention using MANOVA. To test $\mathrm{H} 1$ that participants exposed to a motivational intervention will have greater intentions to register and discuss, we performed ANOVA to compare motivational intervention and non-motivational intervention participant responses to the intention measure, with condition (motivational vs. 
non-motivational) as the factor and intention as the dependent variable. To test $\mathrm{H} 2$ and $\mathrm{H} 3$, we used separate Pearson's chi-square tests to compare 1) the proportion of registering and discussing behaviour for volitional and non-volitional conditions, and 2) the proportion of registering and discussing behaviour across conditions. We used descriptive analyses via frequencies to examine when, where, why, how and with whom registering and discussing occurred for participants responding to these questions.

\section{Results}

\section{Barriers to registering and discussing and suggested solutions (coping plans)}

Participants exposed to a volitional intervention identified up to three obstacles that may prevent them from registering and/or discussing and proposed solutions to the obstacles. Content and thematic analysis of responses showed that there were five barriers common to both communication behaviours: forgetting to register or discuss, having limited time to register or discuss (e.g., too busy, other priorities/commitments take up time, inconvenience), family response (e.g., fear of conflict/disagreement), limited access to the means by which to register (e.g., no access to the internet or local Medicare office) or discuss (e.g., not seeing or communicating with family), and being undecided about organ donation/communicating. Two additional barriers to registering were lack of knowledge about the process of registering (e.g., not knowing eligibility requirements for registering, how or where to register) and barriers which could be termed as 'ick' or 'jinx' factors (see Morgan et al., 2008; O'Carroll et al., 2011) (e.g., 'it is unnatural - against nature', 'God may like the sick person more than me, hence I get killed'). These barriers, however, were endorsed differently by participants depending on the behaviour; 'time', 'lack of knowledge about the process of registering', and 'forgetting', were identified most often as barriers to registering, and 'forgetting', 'access to family', and 'family response' were identified equally as barriers to discussing. 
Solutions proposed to overcome these obstacles included using a prompt or reminder for communication (e.g., diary or setting an email or phone reminder), making time in a busy schedule to register (e.g., using flexi-time at work) or registering online, and arranging a time for family to be together for a discussion (e.g., making sure partner has no other plans) to overcome time and access issues. Using the internet to find information was a solution to lack of knowledge about the process of registration; however, participants did not propose any appropriate solutions to overcome their concerns about the response of family and the potential for conflict when discussing their organ donation wishes with loved ones (e.g., taking a deep breath and doing it, trying to change the other person's attitude).

\section{Strengthening intentions}

A MANOVA was performed on the extended TPB constructs (dependent variables), with condition (motivational vs. non-motivational) as the fixed-factor (Table 2 presents means and standard deviations). There was no significant effect of condition on the extended TPB constructs for registering, $F(6,136)=1.34, p=.242$, partial eta $^{2}=.06$, or discussing, $F(6$, $136)=0.89, p=.503$, partial $e a^{2}=.06$. ANOVAs performed with condition (motivational vs. non-motivational) as the factor and intention as the dependent variable (H1) showed a significant difference in means for intention to register in the motivational $(M=5.08, S D=$ 1.84) compared to non-motivational $(M=4.27, S D=1.94)$ conditions $(F(1,141)=6.52, p$ $=.012$, partial eta ${ }^{2}=.044$ ), but not discuss (motivational $M=5.08, S D=1.84$; nonmotivational $M=5.08, S D=1.84, F(1,92)=.15, p=.702$, partial eta $\left.{ }^{2}=.001\right)$.

\section{Strengthening behaviour}

Chi-square analyses comparing the behaviour of participants exposed to a volitional intervention and participants not exposed to a volitional intervention (H2) showed that a greater proportion of participants in the volitional conditions registered their donation preference during the 1-month follow up period, $\chi^{2}(1, N=139)=6.84, p=.009 .{ }^{3}$ However, 
there was no significant difference in the proportion of participants discussing their donation wishes between volitional and non-volitional conditions, $\chi^{2}(1, N=88)=0.60, p=.439$.

Chi-square analyses were conducted to evaluate which condition was most effective to encourage registering and discussing behaviour (H3). Results revealed a significant difference across the four conditions in the proportion of participants who had registered in the followup period, $\chi^{2}(3, N=139)=9.24, p=.026$, but no significant difference in the proportion of respondents who had discussed their donation wishes, $\chi^{2}(3, N=88)=1.48, p=.688$ (Table 3). A follow-up pairwise comparison evaluated the difference between the proportion of people registering and not registering in the combined condition compared to all other conditions. The pairwise comparison showed a significant difference, $\chi^{2}(1, N=139)=8.05, p$ $=.005$, Cramér's $V=.24$, confirming that $41.9 \%(n=13)$ in the combined condition selfreported registering, compared to $17.6 \%(n=19)$ across all other conditions. In addition, a smaller proportion of people in the combined condition did not register $(n=18,58.1 \%)$ compared to other conditions $(n=89,82.4 \%)$.

\section{Descriptive analyses of registering and discussing behaviour}

Descriptive analyses via frequencies showed when, where, how and with whom (for discussing) registering and discussing behaviour occurred for participants responding to these

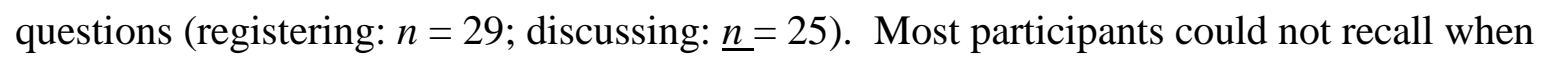
(time/day) communication occurred; consequently, these results are not reported below.

Registering. Most people registered via the internet from home $(n=13)$ or work $(n=$ 7). Seven people registered using a paper form which they either submitted to their local healthcare (i.e. Medicare) office or via post. Two people registered over the phone.

Discussing. Almost half announced they had registered $(n=7)$ or asked if the other person was an organ donor $(n=3)$. Other participants used a prompt to start the conversation such as talking about an organ donation advertisement/TV show $(n=3)$, showing the registry 
card/form/letter $(n=3)$, or mentioning the survey $(n=9)$. Participants communicated their donation wishes to multiple people, most often their partner/spouse $(n=24)$, children $(n=7)$, mother $(n=4)$, close friends $(n=4)$, a sibling $(n=3)$, and work colleague/s $(n=2)$.

\section{Discussion}

To extend previous research which focusses primarily on the motivational aspects underlying decisions to communicate organ donation wishes via registering and discussing, we compared an extended TPB motivational intervention (Sheeran \& Silverman, 2003) to strengthen people's intentions (and ultimately behaviour), a volitional intervention using action and coping planning from the HAPA (Schwarzer, 2008; Sniehotta et al., 2006) to encourage behaviour, and a combined motivational and volitional intervention. For the extended TPB motivational intervention, as expected (H1) participants had stronger intentions to join the AODR demonstrated by higher means for registering intentions in the motivational condition as compared to means for intention in the non-motivational condition; however, there was no difference in means for participants' intentions to discuss their specific donation wishes with family. As hypothesised (H2), the volitional action/coping planning intervention, compared to non-volitional conditions, was successful in increasing registering behaviour (particularly for those participants who were highly motivated to register - Footnote 1); however, there was no effect on discussing. Based on Sheeran and Silverman (2003), it was expected that the combined motivational and volitional intervention would be most likely to increase behaviour (H3). The expected pattern of results held for registering with participants in the combined condition demonstrating the greatest proportion of registering behaviour compared to all other conditions; however, there was no corresponding effect for discussing behaviour.

Overall, specifying when, where, and how joining an organ donor registry will occur and identifying barriers preventing registration and solutions to overcome these barriers (as 
well as strengthening intentions potentially) was an effective approach to increase registration behaviour. This result aligns with much of the organ donation research using motivational models such as the TPB which assume that joining an organ donor registry is a rational or reasoned behaviour (Hyde \& White, 2009; Morgan \& Miller, 2002; Godin et al., 2008; Park \& Smith, 2007). This finding is promising also because it suggests that the barriers to registering donation wishes identified in prior research, and in the current study, such as forgetting and laziness (e.g., Hyde \& White, 2007) can be overcome through planning.

Neither the motivational or volitional intervention was successful in increasing discussing intentions or behaviour. One possibility is that merely completing the survey served as a prompt for discussing, especially since some participants mentioned using the survey to start the conversation, and this mere measurement effect (Godin, Sheeran, Conner, \& Germain, 2008) introduced by the survey masked any intervention effects. Another explanation may be that talking with family about one's specific organ donation preference is not a rational or planned behaviour. Theoretical constructs from models such as the TPB and the HAPA which operate on the assumption that behaviour is largely rational or planned (e.g., Azjen, 1991; Schwarzer, 2008), may not capture the less rational elements (e.g., fear, anticipatory affective reactions, risk, behavioural willingness in response to an external event) associated with decision-making, especially for behaviours that involve consideration of mortality and bodily integrity (Morgan et al., 2008; O'Carroll et al., 2011). While this finding contrasts with previous research using the TPB (or its constructs) to predict conversations with family about organ donation (e.g., Hyde \& White, 2009), it is not entirely inconsistent.

For instance, Hyde and White (2010) found evidence that, in addition to the reasoned aspects of decision-making represented by the TPB, decisions to discuss organ donation wishes may also be reactive and comprise a spontaneous element (as represented in the prototype/willingness model; Gibbons, Gerrard, Blanton, \& Russell, 1998) in response to 
external environmental or situational cues (e.g. another person talking about organ donation or seeing an advertisement promoting organ donation). Although attitudes toward organ donation are generally favourable (Nijkamp et al., 2008), organ donation may not be a topic that people think or talk about unless they are prompted to do so, and discussing donation wishes with family may not occur unless such a prompt is followed by an immediate opportunity to have a discussion (e.g., IIFF model for registering, see Siegel, Alvaro, Crano, Gonzalez, Tang, \& Jones, 2010). In this study, a frequently cited barrier to discussing was 'forgetting', and approximately half of the participants relied on an external cue (e.g., TV advertisement, registration form, or completed survey) as a means to start the conversation rather than using their own internal resources to share their decision. This finding lends support to the idea that including an intervention component that recognises the reactive aspects of conversations about organ donation as well as encouraging individuals to create an immediate opportunity to discuss their donation preference may be beneficial.

Some participants identified fears about the response of their family to a discussion about organ donation as a barrier also, and solutions suggested to overcome such fears (e.g., try to change the other person's attitude, take a deep breath and do it) are likely to lead to an unsuccessful interaction. This finding suggests that, in addition to acknowledging the spontaneous nature of conversations, people may also need greater encouragement to prepare for a conversation, practice it beforehand, identify strategies to cope with conflict once a discussion has started, or to withdraw from a discussion that isn't working with the aim of having a conversation at another time, especially if they have concerns about potential reactions of their loved ones. Alternatively, participants could be encouraged to take the pressure off themselves to have a face-to-face conversation and instead notify family by whatever means is comfortable (e.g., social media, phone, or letter). Without asking participants why they did not discuss their specific organ donation wishes with their loved 
ones, such suggestions are speculative; however, future interventions drawing on alternative decision-making models, such as the IIFF model (Siegel et al., 2010) which maximizes opportunities to translate communication intentions into action, or the Prototype/Willingness model (Gibbons et al., 1998), which considers both the reasoned and reactive elements of decisions to communicate donation wishes, may prove fruitful.

Alternatively, a greater focus on coping planning may be effective to address barriers to discussing donation wishes (e.g., having to justify the donation decision, creating family conflict, not knowing what to say; Thompson et al., 2004); however, the current study design precludes definitive conclusions. Future research could examine the effectiveness of creating separate action and coping plans to encourage communication. Another aspect that has received little attention in the literature but may impact on decisions to talk about donation wishes is the influence of family. Perceived family closeness and family communication patterns as well as family organ donation attitudes or norms may play a key role in the individual's decision to communicate his or her donation preference. Individuals describing a close relationship with family, good general family communication and positive family attitudes and norms for donation may feel more confident to share donation wishes. Future research should continue to explore the complex role of family influence in understanding decisions to communicate donation wishes in theoretical and intervention development (Park, Yun, Smith, \& Morrison, 2010) and persuasive message formation (Scott \& Quick, 2012).

Despite its strengths of using multiple interventions, testing both intentions and behaviour, and using a community sample, limitations of this study should be considered. These limitations include the lack of a true pre-post test design which prevented identification of the cognitive mechanism(s) underlying the strengthening of intentions and any longer term effects of the interventions on attitudes, norms, control, and identity. Furthermore, we did not include a manipulation check or pre-post measures of planning given the potential confound 
such measures may introduce. The small sample size means this study is likely underpowered. A-prior power calculations indicated approximately 70 participants per condition would detect a medium effect size. At Time 1, the number of participants was sufficient; however, the lower than expected response rate at Time 2 (approximately 30\%) precluded more detailed analyses. The small number of responses overall could be due to survey length given that two distinct behaviours and corresponding measures were included or the sensitive topic. To increase future participation strategies could include thank you gifts for each participant (rather than raffle prizes) to acknowledge their time and data collection methods that enable rapport to be established between the researcher and participant (e.g., phone, face-to-face recruitment). Inclusion of phone or electronic reminders may increase survey responses also.

The difference in the number of participants in each condition is also a limitation. Equal numbers of participants in each condition were obtained initially at the point of randomization in Time 1 (Figure 1); however, our examination of two behaviours of which participants may have performed one but not the other or neither, resulted in unequal numbers across conditions. Future studies could consider a design that allows for more flexibility by allocating participants to conditions after their prior behaviour status is known. Differential responding across conditions may also be due to differences in people's motivation to participate and may have introduced bias into the results obtained. Specifically, it is possible that only those participants who were interested in or motivated to communicate their donation wishes completed the intervention (and those less interested participants dropped out), thereby increasing the apparent effectiveness of the intervention.

The higher proportion of Caucasian participants and the use of snowball sampling are additional limitations. Although participants in this study were generally representative of the broader sample of respondents in terms of demographic characteristics (see Footnote 1), there was some variability in the strength of the attitude and moral norm responses in relation to 
registering. Furthermore, we have no way of knowing whether the respondents in this study are representative of the general population, or those people who have communicated their organ donation wishes previously. Future research could address these limitations by comparing the characteristics and motivations of those who have and have not previously registered and discussed their donation wishes, and obtain a more representative sample of the general population. Future research with larger numbers of participants could also consider the potential for communication behaviours to differ on the basis of potentially important demographic characteristics, such as age (younger vs. older respondents) and sex, and control for these factors in analyses or conduct group-based comparisons. It may also be important to ensure that any effect of past communication behaviour is removed by recruiting participants who have not performed either communication behaviour. The small number of participants in this category in the present study prevented meaningful analysis of intervention effects. Finally, although we assessed behaviour, there are associated limitations with self-reported behaviour and future research should attempt to include more objective behavioural measures. Overall, joining an organ donor registry and talking with family about organ donation wishes appear to be different behaviours requiring different interventions. Forming action and coping plans encouraged participants to register their donation wishes but not to discuss with family. Specifically, it was the combined increase in registering intentions and the formation of action and coping plans that produced the greatest proportion of registering behaviour. The results of this study suggest interventions which consider both reasoned and reactive elements may encourage people's discussion of donation wishes with family, a behaviour critical to increasing family consent for organ donation. 


\section{Footnotes}

1. We examined the effect of the motivational intervention on people's intentions only because we believed a one sentence manipulation would be unlikely to produce short-term changes in the extended-TPB cognitions (examination of the means for the extended TPB constructs supported this assumption) (see also Sheeran \& Silverman, 2003).

2. Comparing participants who completed the first survey only (Time 1) with those participants who completed the first and follow up survey (Time 1 and Time 2) and formed the focus of this study (and partialling out any effects of the intervention condition participants were allocated to), we can conclude that participants in the current study were generally representative of respondents with no significant differences between the two groups in age $(t(578)=-1.40, p=.162)$, gender $\left(\chi^{2}(1, N=583)=0.06, p=.801\right)$, or ethnicity $\left(\chi^{2}(1, N=583)=1.62, p=.204\right)$. Furthermore, there were no significant differences in the extended TPB variables for discussing $(F(6,282)=0.59, p=.737)$. In relation to the extended TPB variables for registering, however, there was a significant difference between the two groups on the attitude $(F(1,531)=8.85, p=.003)$ and moral norm measures $(F(1,531)=8.18, p=.004)$, with participants in the Time 1 and Time 2 sample having higher scores on these measures $\left(M_{\text {attitude }}=5.66 ; M_{\text {moral norm }}=4.89\right)$, compared to participants in the Time 1 only sample $\left(M_{\text {attitude }}=5.26 ; M_{\text {moral norm }}=4.22\right)$.

3. To determine if the volitional condition worked only with those who were highly motivated, we ran an independent groups t-test on those exposed to an intervention with a volitional component to determine if there was a difference in intentions between those who did $(n=20)$ and did not $(n=41)$ register at the follow up. There was a significant difference in the means for intention between those exposed to an intervention with a volitional component who performed $(M=5.98, S D=1.36)$ and who did not perform $(M$ $=3.82, S D=2.01)$ behaviour at the follow up, $t(59)=-4.34, p<.001$. 


\section{References}

Ajzen, I. (1991). Theory of planned behavior. Organizational Behavior and Human Decision Processes, 50, 179-211.

DonateLife. (2012a). Facts and Statistics. Retrieved 16th March, 2012, from: http://www.donatelife.gov.au/Discover/Facts-and-Statistics.html

DonateLife. (2012b). Can my family say no, even if I wish to donate? Retrieved $10^{\text {th }}$ July, 2012, from: http://www.donatelife.gov.au/discover/your-questions-answered

Godin, G., Bélanger-Gravel, A., Gagné, C., \& Blondeau, D. (2008). Factors predictive of signed consent for posthumous organ donation. Progress in Transplantation, 18, 109117.

Godin, G., Sheeran, P., Conner, M., \& Germain, M. (2008). Asking questions changes behavior: Mere measurement effects on frequency of blood donation. Health Psychology, 27(2), 179-184.

Gibbons, F. X., Gerrard, M., Blanton, H., \& Russell, D. W. (1998). Reasoned action and social reaction: Willingness and intention as independent predictors of health risk. Journal of Personality and Social Psychology, 74, 1164-1180.

Hyde, M. K., \& White, K. M. (2007). Young Australian adults' knowledge and beliefs about organ donation. Progress in Transplantation, 17, 220-227.

Hyde M. K., \& White, K. M. (2009). To be a donor or not to be? Applying an extended theory of planned behavior to predict posthumous organ donation intentions. Journal of Applied Social Psychology, 39, 880-900.

Hyde, M. K., \& White, K. M. (2010). Are organ donation communication decisions reasoned or reactive? A test of the utility of an augmented Theory of Planned Behaviour with the Prototype/Willingness Model. British Journal of Health Psychology, 15, 435-52.

Morgan, S. E., \& Miller, J. K. (2002). Communicating about the gifts of life: The effect of 
knowledge, attitudes, and altruism on behavior and behavioral intentions regarding organ donation. Journal of Applied Communication Research, 30, 163-178.

Morgan, S. E., Stephenson, M. T., Harrison, T. R., Afifi, W. A., \& Long, S. D. (2008). Facts versus 'feelings': How rational is the decision to become an organ donor? Journal of Health Psychology, 13, 644-658.

National Clinical Taskforce on Organ Donation [NCTOTD], (2008). National Clinical Taskforce on Organ and Tissue Donation final report: Think nationally, act locally. Commonwealth of Australia, 2008.

Nijkamp, M. D., Hollestelle, M. L., Zeegers, M. P., van den Borne, B., \& Reubsaet, A. (2008). To be(come) or not to be(come) an organ donor, that's the question: A metaanalysis of determinant and intervention studies. Health Psychology Review, 2, 20-40.

O’Carroll, R. E., Foster, C., McGeechan, G., Sandford, K., \& Ferguson, E. (2011). The 'ick' factor, anticipated regret, and willingness to become an organ donor. Health Psychology, 30, 236-245.

Park, H. S., \& Smith, S. W. (2007). Distinctiveness and influence of subjective norms, personal descriptive and injunctive norms, and societal descriptive and injunctive norms on behavioral intent: A case of two behaviors critical to organ donation. Human Communication Research, 33, 194-218.

Park, H. S., Yun, D., Smith, S. W., \& Morrison, K. (2010). Family communication patterns and willingness to engage in family discussion about organ donation in the United States. Global Journal of Health Science, 2, 61-71.

Rosenblum, A. M., Horvat, L. D., Siminoff, L. A., Prakash, V., Beitel, J., \& Garg, A. X. (2011). The authority of next-of-kin in explicit and presumed consent systems for deceased organ donation: an analysis of 54 nations. Nephrology, Dialysis, Transplantation. doi: 10.1093/ndt/gfr619 
Schwarzer, R. (2008). Modeling health behavior change: How to predict and modify the adoption and maintenance of health behaviors. Applied Psychology, 57, 1-29.

Scott, A. M., \& Quick, B. L. (2012). Family communication patterns moderate the relationship between psychological reactance and willingness to talk about organ donation. Health Communication. doi: 10.1080/10410236.2011.635135

Sheeran, P., \& Silverman, M. (2003). Evaluation of three interventions to promote workplace health and safety: evidence for the utility of implementation intentions. Social Science and Medicine, 56, 2153-2163.

Siegel, J. T., Alvaro, E. M., Crano, W. D., Lac, A., Ting, S., \& Jones, S. P. (2008). A quasiexperimental investigation of message appeal variations on organ donor registration rates. Health Psychology, 27, 170-178.

Siegel, J. T., Alvaro, E. M., Crano, W. D., Gonzalez, A. V., Tang, J. C., \& Jones, S. P. (2010). Passive-positive organ donor registration behavior: a mixed method assessment of the IIFF Model. Psychology, Health \& Medicine, 15, 198-209.

Siminoff, L. A., Gordon, N., Hewlett, J., \& Arnold, R. M. (2001). Factors influencing families' consent for donation of solid organs for transplantation. Journal of the American Medical Association, 286, 71-76.

Sniehotta, F. F., Schwarzer, R., Scholz, U., Schüz, B. (2005). Action planning and coping planning for long-term lifestyle change: theory and assessment. European Journal of Social Psychology, 35, 565-576.

Sniehotta, F. F., Scholz, U., \& Schwarzer, R. (2006). Action plans and coping plans for physical exercise: A longitudinal intervention study in cardiac rehabilitation. British Journal of Health Psychology, 11, 23-37.

Thompson, T. L., Robinson, J. D., Kenny, R. W. (2004). Family conversations about organ donation. Progress in Transplantation, 14, 49-55. 
Invitation sent to Australian residents aged 18 years and older

Participants who had not previously registered and/or discussed responded

$$
N=584^{\dagger}
$$

( $n=545$ not registered; $n=268$ not discussed)

Participants initially allocated randomly to:

Motivational condition $(n=148)$, Volitional condition $(n=141)$, Combined condition $(n=143)$, or Control condition $(n=152)$

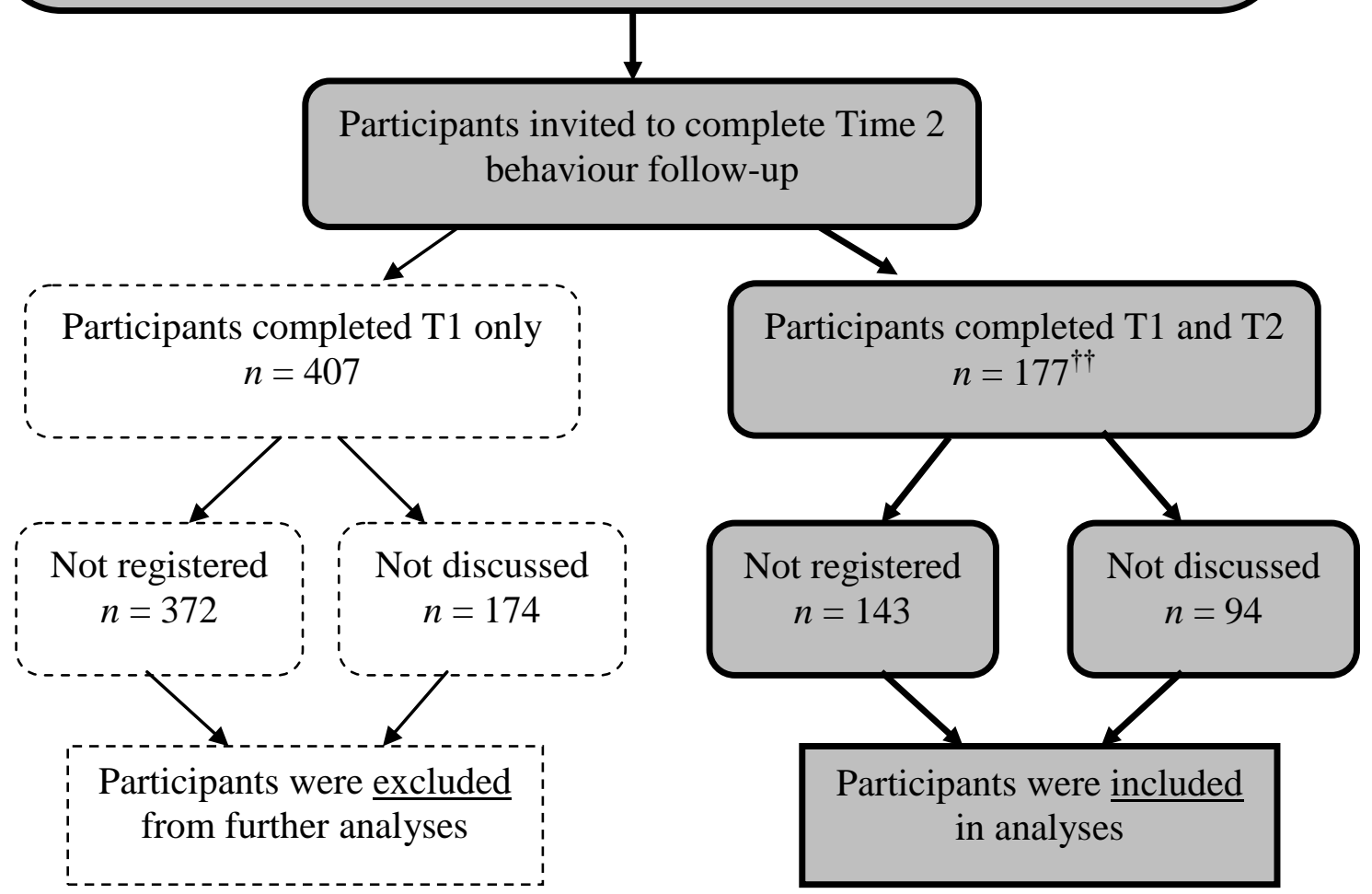

${ }^{\dagger}$ Please note that some participants provided data for both behaviours; therefore, the number of responses exceeds the total number of participants.

† This sample comprised 103 participants who had not registered but who had discussed, 54 participants who had not discussed but who had registered, and 40 participants who had neither registered nor discussed.

Figure 1. Flow chart of participation and participant breakdown for analyses. 


\section{Definition of Registering}

For registering, participants were informed that "when we talk about registering we mean: signing a registration form from the Australian Organ Donor Register to indicate your consent/non-consent to donate your organs upon death. If you have registered your consent/non-consent you should have a card that looks like the one on the left" (picture of card shown).

\section{Definition of Discussing}

For discussing, participants read the following definition: "when we talk about discussing we mean: telling your family, partner, or significant other your specific decision to donate your organs upon death. Even if you have registered your consent/non-consent to donate your organs your partner or family members will still be consulted to confirm your decision in the event of your death. This means that whether you have registered your decision or not it is advisable that you tell your partner and family members your specific preference for organ donation. Many people have had conversations about organ donation generally but have not told their family their specific donation preference."

Figure 2. Definitions of registering and discussing provided to participants. 
Table 1

Demographic Characteristics, Preference for, Knowledge About, and Prior Experience with Organ Donation for Participants Providing Time 1 and Time 2 Data $(N=177)$

\section{Condition allocated to}

\begin{tabular}{|c|c|c|c|c|c|}
\hline Variable & & $\begin{array}{l}\text { Motivational } \\
(\mathrm{n}=42)\end{array}$ & $\begin{array}{l}\text { Volitional } \\
(\mathrm{n}=36)\end{array}$ & $\begin{array}{l}\text { Combined } \\
(\mathrm{n}=38)\end{array}$ & $\begin{array}{l}\text { Control } \\
(n=61)\end{array}$ \\
\hline \multirow[t]{2}{*}{ Gender $^{a}$} & Male & 19 & 15 & 15 & 24 \\
\hline & Female & 23 & 21 & 23 & 37 \\
\hline \multirow[t]{3}{*}{ Age in years ${ }^{b}$} & Mean & 46.90 & 46.69 & 46.19 & 48.79 \\
\hline & SD & 14.95 & 16.42 & 15.46 & 13.83 \\
\hline & Min-Max & $23-80$ & $23-80$ & $23-76$ & $18-70$ \\
\hline \multirow[t]{2}{*}{ Ethnicity $^{\mathrm{c}}$} & Caucasian & 40 & 34 & 37 & 59 \\
\hline & Non-Caucasian & 2 & 2 & 1 & 2 \\
\hline Relationship & Single & 6 & 10 & 14 & 16 \\
\hline status & In a relationship & 36 & 26 & 24 & 45 \\
\hline State/Territory & NSW & 23 & 11 & 16 & 19 \\
\hline \multirow[t]{2}{*}{ residing in } & QLD & 12 & 18 & 16 & 27 \\
\hline & Other & 6 & 6 & 6 & 13 \\
\hline \multirow{3}{*}{$\begin{array}{l}\text { Organ donation } \\
\text { preference }\end{array}$} & Preference to donate & 36 & 25 & 34 & 49 \\
\hline & Prefer to not donate & 1 & 5 & 0 & 2 \\
\hline & Undecided & 5 & 6 & 4 & 10 \\
\hline Knowledge (1 & Mean & 4.71 & 4.19 & 4.42 & 4.44 \\
\hline very poor -7 & SD & 1.13 & 1.33 & 0.98 & 1.13 \\
\hline excellent) ${ }^{d}$ & Min-Max & $2-7$ & $2-7$ & $2-6$ & $2-7$ \\
\hline Knew donor/ & Yes & 11 & 14 & 10 & 24 \\
\hline recipient & No & 31 & 22 & 28 & 37 \\
\hline Needs/received & Yes & 0 & 1 & 0 & 1 \\
\hline a transplant & No & 42 & 36 & 38 & 60 \\
\hline
\end{tabular}

Across conditions there was no significant difference in: ${ }^{a}$ the proportion of males and females, $\chi^{2}(3, N=177)=0.42, p=.93{ }^{b}$ the mean age in years of participants, $F(3,172)=$ $0.30, p=.828 ;{ }^{c}$ the proportion of Caucasian and non-Caucasian participants, $\chi^{2}(1, N=177)$ $=0.56, p=.905$; or $^{\mathrm{d}}$ the mean score for self-reported organ donation knowledge, $F(3,173)=$ $1.35, p=.259$. 
Table 2

Means (Standard Deviations) for Participant Responses to Theory of Planned Behaviour

Constructs Based on Exposure to a Motivational or Non-Motivational Intervention Condition for Registering and Discussing

\begin{tabular}{|c|c|c|c|}
\hline \multirow[t]{2}{*}{ Construct } & \multirow[t]{2}{*}{ Condition $^{\mathrm{a}}$} & Registering & Discussing \\
\hline & & $M(S D)$ & $M(S D)$ \\
\hline \multirow[t]{2}{*}{ Attitude } & Motivational & $5.94(1.21)$ & $5.20(1.40)$ \\
\hline & Non-motivational & $5.58(1.43)$ & $5.48(1.33)$ \\
\hline \multirow[t]{2}{*}{ Subjective norm } & Motivational & $4.67(1.22)$ & $4.11(1.30)$ \\
\hline & Non-motivational & $4.50(1.45)$ & $4.22(1.45)$ \\
\hline \multirow[t]{2}{*}{ PBC } & Motivational & $5.84(1.02)$ & $5.26(1.26)$ \\
\hline & Non-motivational & $5.52(1.33)$ & $5.35(1.33)$ \\
\hline \multirow[t]{2}{*}{ Moral norm } & Motivational & $5.17(1.49)$ & $4.58(1.36)$ \\
\hline & Non-motivational & $4.69(1.69)$ & $4.40(1.87)$ \\
\hline \multirow[t]{2}{*}{ Self-identity } & Motivational & $3.71(0.58)$ & $3.56(0.65)$ \\
\hline & Non-motivational & $3.65(0.68)$ & $3.66(0.77)$ \\
\hline \multirow[t]{2}{*}{ Intention } & Motivational & $5.08(1.84)$ & $4.46(1.72)$ \\
\hline & Non-motivational & $4.27(1.94)$ & $4.33(1.83)$ \\
\hline
\end{tabular}

\footnotetext{
${ }^{\mathrm{a}}$ Respondents comprised 143 participants for registering (Motivational intervention $n=67$; non-motivational $n=76$ ) and 93 participants for discussing (Motivational intervention $n=36$; non-motivational $n=57$ ).
} 
Table 3

Observed Counts and Percentages for Registering and Discussing Behaviour for Participants Across all Conditions.

$$
\text { Registering behaviour }(N=139)
$$

\begin{tabular}{llll} 
Condition & Yes $(\%)$ & No $(\%)$ & $n$ \\
\hline Motivational & $5(14.3 \%)$ & $30(85.7 \%)$ & 35 \\
Volitional & $7(25.0 \%)$ & $21(75.0 \%)$ & 28 \\
Combined & $13(41.9 \%)$ & $18(58.1 \%)$ & 31 \\
Control & $7(15.6 \%)$ & $38(84.4 \%)$ & 45 \\
\hline Condition & Discussing behaviour $(N=88)$ & $n$ \\
\hline Motivational & Yes $(\%)$ & No $(\%)$ & 19 \\
Volitional & $6(31.6 \%)$ & $13(68.4 \%)$ & 20 \\
Combined & $4(20.0 \%)$ & $16(80.0 \%)$ & 18 \\
Control & $6(33.3 \%)$ & $12(66.7 \%)$ & 31 \\
\hline
\end{tabular}

